\title{
Comparing the effectiveness of acceptance and commitment therapy and physiotherapy on quality of life and pain catastrophizing in patients with chronic pain
}

\author{
Mahnaz Ghatreh Samani ${ }^{\mathbb{D}}$, Mahmoud Najafi: ${ }^{* \mathbb{D}}$, Isaac Rahimian Boogar \\ Department of Clinical Psychology, Semnan University, Semnan, Iran.
}

*Corresponding Author: Mahmoud Najafi, Associate Professor, Department of Clinical Psychology, Semnan University, Semnan, Iran, Phone number: 0233362330,Email: m_najafi@semnan.ac.ir

\begin{abstract}
Background and aims: Chronic pain is a common health problem that affects various aspects of life. Acceptance and commitment therapy (ACT) seems to be helpful in improving the quality of life and pain catastrophizing in patients with chronic pain. The purpose of this study was to compare the efficacy of ACT and physiotherapy on quality of life and pain catastrophizing in patients with chronic pain.

Methods: The subjects were 75 women suffering from chronic pain who were considered for physiotherapy. They were randomly divided into 3 groups including ACT, physiotherapy, and control groups. The control group consisted of 25 patients who were on the waiting list for physiotherapy. The first group participated in 8 sessions of ACT, the second group attended 10 sessions of physiotherapy, and the control group received no treatment. The Pain Catastrophizing Scale (PCS) developed by Sullivan et al and the World Health Organization Quality of Life (WHOQOL-BREF) questionnaire were used in this study.

Results: The results showed that the quality of life in the ACT group was significantly higher than that in the physiotherapy group and control group $(P<0.001)$. Moreover, there was no significant difference between the ACT and physiotherapy groups in reducing pain catastrophizing $(P>0.05)$, while this difference was significant between the ACT and control groups $(P<0.001)$.

Conclusion: In general, ACT leads to a reduction in pain catastrophizing and an increase in the quality of life of patients with chronic pain. Therefore, beside the current therapy like physiotherapy, ACT can be used as another therapeutic choice for patients with chronic pain. Keywords: Acceptance and commitment therapy, Pain catastrophizing, Quality of life
\end{abstract}

Received: 2 March 2019, Accepted: 26 May 2019, ePublished: 31 December 2019

\section{Introduction}

Chronic pain is a common health problem that can affect all aspects of an individual's life and lead to a decrease in quality of life (1). People with chronic pain may not have a physical problem with their pain; in these patients, psychological factors play a major role in the onset and continuation of pain. The severity of psychological pains does not change with taking medication. Chronic pain has several aspects such as the amount of perceived pain, disability, and mood associated with it (2). The severity of chronic pain can fall on a spectrum: low levels of pain determine intensity, while high levels in addition to the severity of pain determine the amount of life-related disability and daily activities associated with chronic pain (3). Among middle-aged people, chronic pain is associated with poorer cognitive function, physical inability, and diminished daily functions (4).

According to the World Health Organization (WHO), the quality of life is the understanding of individuals from their place of life in terms of culture, the value system in which they live, their goals, expectations, standards, and priorities (5). It has been proven that chronic pain has a negative impact on quality of life, along with negative consequences on general health and social and psychological dimensions of an individual's life. Quality of life does not mean a person has no physical problems, as some people with a disability or physical illness have a good quality of life because of their lifestyle (6). Chronic pain reduces the quality of life of patients who cannot properly handle or restrict their daily activities. Patients with chronic pain, in order to cure their pain, may spend a lot of time in health care systems (7). Quality of life in elderly people with chronic pain, on the other hand, is even very low. These people report clinical insomnia which is an important problem in people with chronic pain and affects their quality of life (8).

Beliefs are steady thoughts. There are two types of beliefs: attributions and expectations. Attribution is

(C) 2019 The Author(s); Published by Shahrekord University of Medical Sciences. This is an open-access article distributed under the terms of the Creative Commons Attribution License (http://creativecommons.org/licenses/by/4.0), which permits unrestricted use, distribution, and reproduction in any medium, provided the original work is properly cited. 
interpretation of pain, while expectation is thoughts with predicted consequences. Attributions and expectations have direct and indirect effects on compatibility. Coping with pain as a target can have a negative consequence (9). Pain catastrophizing causes extreme concentration on physical symptoms and more disability in people (10). The belief that pain is understandable is associated with better treatment, while the belief that pain is mysterious is associated with more catastrophic pain (11). The clinical strategy for the reduction of pain catastrophizing is cognitive reconstruction (1). Cognitive reconstruction refers to not only psychological implications, but also the activities of the neuronal system involved in the perception of pain; therefore, maladaptive knowledge of pain such as the catastrophic pain is associated with emotional and behavioral responses (12). Pain behaviors are a tool that gets help and protection of others (13). Pain-related behaviors may cause others to act and hence promote the care (14). Pain catastrophizing may be associated with inefficiency and depression, because patients with chronic pain cannot escape the pain or keep others' attention for a long time (15). The fear avoidance model assumes that the pain catastrophizing causes increased fear of injury when moving. Moreover, catastrophic pain is associated with personality traits such as neurotic pessimism and pessimism (16). People with less pain catastrophizing thoughts tend to reform their beliefs about pain. It is possible that pain catastrophizing is associated with worry (17). Patients with less pain catastrophizing increase their control of emotions and are more likely to be compatible (18).

Physiotherapy methods are used to maintain and increase the physical, psychological, and social efficacy of humans. Physiotherapy is a profession that uses knowledge, assessment, and physical intervention for the treatment of patients (19). The effect of physiotherapy on chronic pain and function of individuals with osteoporosis has shown that physical therapy can affect quality of life, increase daily function, and decrease the degree of pain in these people (20). People who suffer from rheumatological disorders like fibromyalgia have a severe chronic pain in the musculoskeletal system. Individuals with this condition improved their quality of life, while receiving cognitive physiotherapy (21).

A strong correlation between pain and disability leads many treatment approaches to focus on reducing pain, while psychological approaches focus on changing responses to chronic pain (22). Chronic pain is a major health problem that is associated with depression and other psychological disorders.

Acceptance and commitment therapy (ACT) is based on a psychological flexibility model. The model of psychological flexibility consists of six central and interrelated processes including acceptance, diffusion, being present, values, committed action, and self as context (23). This intervention seeks to change the function of events and the individuals' relationship with them through strategies such as mindfulness, acceptance, or cognitive diffusion (24).

ACT is not about controlling or coping with pain, but is more emphatic in accepting the pain (25). ACT implies the concepts of mental suffering mainly due to cognitive complexities, experiential avoidance, and psychological inflexibility that impede an individual's ability to perform valuable behaviors (26). This intervention often targets undesirable influences of language and thought processes on behavior. One of its methods is using empirical methods and changing behavior directly. Exposure, mindfulness exercises, emotional exercises, role-playing, and methods that make diffusion can act in this non-verbal experience. From a slightly different perspective, ACT and related theories can be considered as a kind of self-help (27) .

Despite studies on the effectiveness of ACT and physiotherapy on different aspects of life and chronic pain, to the best of our knowledge, no study has compared the effectiveness between ACT and physiotherapy. Sometimes pain may be relieved with a medication for a short time, but this temporary effect will still cause the former mental problems after the pain returns; therefore, in this study we evaluated what kinds of treatment can improve the quality of life and pain catastrophizing in patients with chronic pain.

\section{Materials and Methods}

This quasi-experimental study compared the effectiveness of ACT and physiotherapy on quality of life and pain catastrophizing in patients with chronic pain during a two-month period in Isfahan city, Iran. All patients with chronic pain in Isfahan who had been diagnosed with chronic pain by physicians and referred to physiotherapy institutes constituted the study subjects. In this study, 75 women who suffered from chronic pain and were in need of physiotherapy were randomly divided into 3 groups: 25 patients in ACT group, 25 patients in the physiotherapy group, and 25 patients on the waiting list as the control group. Inclusion criteria were being in the age range of 30 to 65 years, having at least three months of chronic pain, not having disabling chronic pain, and not receiving other interventions. Exclusion criteria were not attending more than two sessions and having concurrent mental disorders. Initially, informed consent was obtained from all the patients for participating in the study. They were also assured of the confidentiality of the information. Furthermore, the World Health Organization Quality of Life (WHOQOL-BREF) Questionnaire and the Pain Catastrophizing Scale (PCS) developed by Sullivan et al. (1995) were used in this study (28).

WHOQOL-BREF questionnaire was compiled by a group in the World Health Organization (WHO). It measures 6 areas of physical health, mental health, social relationships, environmental health, health status, and quality of life. Questions 1 and 2 are used for assessing the 
self-perception of quality of life and are not included in the scoring. Score 1 for the" worst" and score 5 for the "best" are assigned to all questions except 3, 4, and 26. A higher score indicates a better quality of life. The reliability values are within the cluster correlation index of 0.77 in the physical health, 0.77 in the psychological domain, 0.75 in the social relationship, and 0.84 in the physical health. Additionally, the Cronbach alpha of the four domains in the healthy and patient groups are 0.73 and 0.77 (29).

PCS: This questionnaire has 13 questions and is based on the Likert scale, which is 1 to 5 (no $=1$, somewhat $=2$, average $=3$, high $=4$, all times $=5$ ). The Cronbach's alpha for the total score of the pain catastrophizing is 0.87 (30). The reliability of this questionnaire is more than 0.92 (31).

The treatment guide for this intervention was adopted from "life with chronic pain" book (32). Table 1 shows the description of the sessions.

At first, the patients completed the pre-test questionnaires. Then, the women in ACT group participated in eight weekly sessions. Patients in the physiotherapy group received 10 sessions of therapy by a physiotherapist, while patients in the control group did not receive any therapy. In the end, post-test questionnaires were completed by the participants. Data were analyzed by SPSS software version 21.0 and multivariate analysis of covariance (MANCOVA) was used for data analysis.

\section{Results}

At first, the assumption of normality in the score distribution was examined. The Kolmogorov-Smirnov test showed that the variables in all groups were normally distributed. The mean and standard deviation of variables are shown in Table 2.

The results showed that there was a significant difference between post-test findings of ACT, physiotherapy, and control groups in terms of quality of life and pain

\section{catastrophizing.}

The hypothesis of homogeneity of regression slopes showed that the interaction between the groups and variables was higher than the alpha level $(P>0.05),\left(\mathrm{F}_{(3)}=0.74\right.$, $P=0.53$ in quality of life; and $\mathrm{F}_{(3)}=1.05, P=0.37$ in pain catastrophizing); therefore, the assumption of homogeneity of regression slopes had not been broken. In addition, the Levene test examined the equality of intergroup variances. The significance level of Levene test in the quality of life and pain catastrophizing were greater than 0.05 . Thus the assumption of equality of error variances was considered. The MANCOVA also showed that the effectiveness of physiotherapy and ACT on the quality of life and pain catastrophizing was significant $(P<0.001)$.

Table 3 shows the difference between the two groups in terms of mean. Based on the results, there was a significant difference between the ACT and physiotherapy groups regarding the quality of life $(P<0.05)$ as ACT increased the quality of life more than physiotherapy. However, there was no significant difference between the ACT and physiotherapy groups in terms of pain catastrophizing. Moreover, there was a significant difference between the ACT and control groups on pain catastrophizing $(P<0.05)$.

\section{Discussion}

The results of this study indicated that the mean scale of ACT in improving the quality of life was more than that of physiotherapy. In addition, ACT and physiotherapy had the same effect on the reduction of pain catastrophizing. Consistent with our results, Stone et al. showed that patients with chronic pain who received ACT had better quality of life than the control group and also their anxiety level was decreased (33). One study on the quality of life of women with chronic pelvic pain showed that the pain intensity in patients had an inverse relationship with their quality of life. It was shown in this study that pain intensity

Table 1. Description of sessions

\begin{tabular}{|c|c|}
\hline Sessions & Description \\
\hline First session & $\begin{array}{l}\text { A survey on the purpose of group therapy for the treatment of chronic pain; creative resilience training; current strategies for chronic pain, } \\
\text { and a comparison between the advantages and disadvantages of these strategies; and presenting a homework for the upcoming meeting }\end{array}$ \\
\hline Second session & $\begin{array}{l}\text { Reviewing the tasks of the previous session; changing the behavior and mindfulness; introducing the model of behavior change; the } \\
\text { relationship between thoughts, emotions, and physiological functions; teaching the first practice of mindfulness with regard to breathing } \\
\text { exercises; and providing a homework for the upcoming meeting }\end{array}$ \\
\hline Third session & $\begin{array}{l}\text { Reviewing the task of the previous session; clarifying the values and comparing them with goals; identifying the values of the group } \\
\text { members; specifying the concept of acceptance; practicing mindfulness; and presenting the homework for the upcoming meeting }\end{array}$ \\
\hline Forth session & $\begin{array}{l}\text { Reviewing the tasks of the previous session; clarifying the values, goals, and obstacles on these values; separating personal values from } \\
\text { other values and clarifying personal values; practicing mindfulness; and presenting a homework for the upcoming meeting }\end{array}$ \\
\hline Fifth session & $\begin{array}{l}\text { Reviewing the tasks of the previous session; reviewing the issue of the diffusion and commitment to action by using the values; recognizing } \\
\text { the barriers that affect the values of group members; and presenting the assignment for the upcoming meeting }\end{array}$ \\
\hline Sixth session & $\begin{array}{l}\text { Reviewing the task of the previous session; planning for exercising values; teaching the exercises of mindfulness and self-observation; and } \\
\text { presenting the assignment for the upcoming meeting }\end{array}$ \\
\hline Seventh session & $\begin{array}{l}\text { Reviewing the task of the previous session; examining the consent to participate in an unpleasant act; commitment to barriers; mindfulness } \\
\text { practice; and presentation of the assignment for the upcoming meeting. }\end{array}$ \\
\hline Eighth session & Reviewing the task of the previous session; reviewing the progress of the individuals; and explaining how to prevent relapse of the disease \\
\hline
\end{tabular}


Table 2. Mean and standard deviation of variables in pre-tests and post-tests for all the study groups

\begin{tabular}{llcc}
\hline \multirow{2}{*}{ Variable } & Group & Pre-test & Post-test \\
\cline { 3 - 4 } & & Mean \pm SD & mean \pm SD \\
\hline \multirow{2}{*}{ Quality of life } & ACT & $77.65 \pm 13.53$ & $84.83 \pm 14.27$ \\
& Physiotherapy & $66.45 \pm 12.28$ & $69.55 \pm 14.67$ \\
& Control & $17.50 \pm 73.60$ & $15.31 \pm 17.50$ \\
Pain catastrophizing & ACT & $33.22 \pm 11.73$ & $29.39 \pm 8.79$ \\
& Physiotherapy & $33.60 \pm 8.33$ & $31.70 \pm 8.39$ \\
& Control & $29 \pm 8.19$ & $32.25 \pm 8.16$ \\
\hline
\end{tabular}

Table 3. Comparison of the treatment groups with the related control groups using the LSD method

\begin{tabular}{|c|c|c|c|c|}
\hline Variable & Treatment Groups & Control groups & Mean difference & P value \\
\hline \multirow{3}{*}{ Quality of life } & \multirow{2}{*}{ ACT } & Physiotherapy & $9.39 \pm 3.74$ & 0.01 \\
\hline & & Control & $11.55 \pm 3.61$ & 0.01 \\
\hline & Physiotherapy & Control & $2.15 \pm 3.84$ & 0.57 \\
\hline \multirow{3}{*}{$\begin{array}{l}\text { Pain } \\
\text { catastrophizing }\end{array}$} & \multirow{2}{*}{ ACT } & Physiotherapy & $-2.74 \pm 1.89$ & 0.15 \\
\hline & & Control & $-5.85 \pm 1.82$ & 0.01 \\
\hline & Physiotherapy & Control & $-3.10 \pm 1.94$ & 0.11 \\
\hline
\end{tabular}

was a very important factor in predicting quality of life and its dimensions, especially physical dimension (34). One of the values that is applied in ACT is mindfulness. The effectiveness of this intervention was supported by the improvement of quality of life in patients with low back pain (35). Cancer is one of the very painful diseases. The quality of life of women with breast cancer who underwent rehabilitation programs including physiotherapy, self-care education, and intervention was significantly higher than the quality of life of patients who did not participate in these programs (36). Physiotherapy with depression and anxiety intervention increased the effectiveness of physical therapy and improved the quality of life of patients (37). Furthermore, the results of this study are in line with the research that showed patients who received ACT reported less self-dissatisfaction with their pain, because ACT emphasizes psychosocial flexibility (38). According to a study by Baxter et al., the consequences of pain can be depression and pain catastrophizing (39). Catastrophizing is a central variable for fear and avoidance, through which a negative evaluation of pain and fear leads to an increased pain relief in patients. The results of a study showed that ACT reduced pain catastrophizing in the treatment group compared to the control group. It also reduced the pain in women with chronic pelvic pain as declared in the followup phase (40).

\section{Conclusion}

To conclude, ACT can improve the quality of life and psychological flexibility of patients with chronic pain and also decrease the pain catastrophizing. Therefore, beside the current therapy for patients with chronic pain, ACT could be a very good choice of treatment. In addition, it is really helpful for the patient's self-awareness which increases the attention of patients to the related therapy and treatment follow-up. It also improves social health levels.

\section{Limitations of the study}

It is plausible that some limitations have influenced the results obtained. Lack of time and access to the sample and the impossibility of treatment for a specific type of chronic pain, chronic back pain, or chronic leg pain are instances of the limitations of this study. This study was conducted only on women with chronic pain; therefore, the results could not be generalized to the male society. It is suggested that such research be conducted on male society in future, and follow-up should be made to determine the effectiveness of treatment in follow-up periods.

\section{Conflict of Interests}

Authors declare no conflict of interests.

\section{Ethical considerations}

This study was approved by Semnan University and the announcement of research code of the dissertation (98/96/25501) was made on 01.31.2018.

\section{Acknowledgment}

Authors sincerely thank the staff of Dr. Shariati Hospital in Isfahan, Iran, and all the women who participated in this study.

\section{References}

1. Jensen MP, Smith AE, Alschuler KN, Gillanders DT, Amtmann $\mathrm{D}$, Molton IR. The role of pain acceptance on function in individuals with disabilities: a longitudinal study. Pain. 2016;157(1):247-54. doi: 10.1097/j.pain.0000000000000361.

2. Gatchel RJ, Turk DC. Psychosocial Factors in Pain: Critical Perspectives. New York: Guilford Press; 1999. p. 510.

3. Von Korff M, Ormel J, Keefe FJ, Dworkin SF. Grading the severity of chronic pain. Pain. 1992;50(2):133-49. doi: 10.1016/03043959(92)90154-4.

4. Wetherell JL, Petkus AJ, Alonso-Fernandez M, Bower ES, Steiner AR, Afari N. Age moderates response to acceptance and commitment therapy vs. cognitive behavioral therapy for chronic pain. Int J Geriatr Psychiatry. 2016;31(3):302-8. doi: 10.1002/gps.4330.

5. Nejat S. Quality of life and its measurement. Iran J Epidemiol. 2008;4(2):57-62. [Persian].

6. Lamé IE, Peters ML, Vlaeyen JW, Kleef M, Patijn J. Quality of life in chronic pain is more associated with beliefs about pain, than with pain intensity. Eur J Pain. 2005;9(1):15-24. doi: 10.1016/j. ejpain.2004.02.006.

7. Cederberg JT, Cernvall M, Dahl J, von Essen L, Ljungman G. Acceptance as a mediator for change in acceptance and commitment therapy for persons with chronic pain? Int J Behav Med. 2016;23(1):21-9. doi: 10.1007/s12529-015-9494-y.

8. Dragioti E, Bernfort L, Larsson B, Gerdle B, Levin LÅ. Association of insomnia severity with well-being, quality of life and health care costs: a cross-sectional study in older adults with chronic pain (PainS65+). Eur J Pain. 2018;22(2):414-25. doi: 10.1002/ejp.1130.

9. Spinhoven P, Ter Kuile M, Kole-Snijders AM, Hutten Mansfeld M, Den Ouden DJ, Vlaeyen JW. Catastrophizing and internal pain control as mediators of outcome in the multidisciplinary treatment of chronic low back pain. Eur J Pain. 2004;8(3):2119. doi: 10.1016/j.ejpain.2003.08.003. 
10. Kratz AL, Ehde DM, Bombardier $\mathrm{CH}$, Kalpakjian $\mathrm{CZ}$, Hanks RA. Pain acceptance decouples the momentary associations between pain, pain interference, and physical activity in the daily lives of people with chronic pain and spinal cord injury. J Pain. 2017;18(3):319-31. doi: 10.1016/j.jpain.2016.11.006.

11. Stroud MW, Thorn BE, Jensen MP, Boothby JL. The relation between pain beliefs, negative thoughts, and psychosocial functioning in chronic pain patients. Pain. 2000;84(2-3):34752. doi: 10.1016/s0304-3959(99)00226-2.

12. Schütze R, Rees $C$, Preece $M$, Schütze $M$. Low mindfulness predicts pain catastrophizing in a fear-avoidance model of chronic pain. Pain. 2010;148(1):120-7. doi: 10.1016/j. pain.2009.10.030.

13. Sullivan MJ, Adams $H$, Sullivan ME. Communicative dimensions of pain catastrophizing: social cueing effects on pain behaviour and coping. Pain. 2004;107(3):220-6. doi: 10.1016/j.pain.2003.11.003.

14. Vervoort T, Goubert L, Eccleston C, Vandenhende M, Claeys O, Clarke J, et al. Expressive dimensions of pain catastrophizing: an observational study in adolescents with chronic pain. Pain. 2009;146(1-2):170-6. doi: 10.1016/j.pain.2009.07.021.

15. Cano A. Pain catastrophizing and social support in married individuals with chronic pain: the moderating role of pain duration. Pain. 2004;110(3):656-64. doi: 10.1016/j. pain.2004.05.004.

16. Turner JA, Jensen MP, Romano JM. Do beliefs, coping, and catastrophizing independently predict functioning in patients with chronic pain? Pain. 2000;85(1-2):115-25. doi: 10.1016/ s0304-3959(99)00259-6.

17. Van Damme S, Crombez G, Eccleston C. Retarded disengagement from pain cues: the effects of pain catastrophizing and pain expectancy. Pain. 2002;100(1-2):1118. doi: 10.1016/s0304-3959(02)00290-7.

18. Woby SR, Watson PJ, Roach NK, Urmston M. Are changes in fear-avoidance beliefs, catastrophizing, and appraisals of control, predictive of changes in chronic low back pain and disability? Eur J Pain. 2004;8(3):201-10. doi: 10.1016/j. ejpain.2003.08.002.

19. Jones R, Carter J, Moore P, Wills A. A study to determine the reliability of an ankle dorsiflexion weight-bearing device. Physiotherapy. 2005;91(4):242-9. doi: 10.1016/j. physio.2005.04.005.

20. Malmros B, Mortensen L, Jensen MB, Charles P. Positive effects of physiotherapy on chronic pain and performance in osteoporosis. Osteoporos Int. 1998;8(3):215-21. doi: 10.1007/ s001980050057.

21. Vitorino DF, Carvalho LB, Prado GF. Hydrotherapy and conventional physiotherapy improve total sleep time and quality of life of fibromyalgia patients: randomized clinical trial. Sleep Med. 2006;7(3):293-6. doi: 10.1016/j.sleep.2005.09.002.

22. Vowles KE, Fink BC, Cohen LL. Acceptance and Commitment Therapy for chronic pain: a diary study of treatment process in relation to reliable change in disability. J Contextual Behav Sci. 2014;3(2):74-80. doi: 10.1016/j.jcbs.2014.04.003.

23. Yu L, Norton S, McCracken LM. Change in "self-ascontext"("perspective-taking") occurs in acceptance and commitment therapy for people with chronic pain and is associated with improved functioning. J Pain. 2017;18(6):66472. doi: 10.1016/j.jpain.2017.01.005

24. Hunot V, Moore TH, Caldwell D, Davies P, Jones H, Lewis G, et al. Mindfulness-based 'third wave' cognitive and behavioural therapies versus other psychological therapies for depression. Cochrane Database Syst Rev. 2010(9). doi: 10.1002/14651858. cd008704.

25. Veehof MM, Oskam MJ, Schreurs KM, Bohlmeijer ET.
Acceptance-based interventions for the treatment of chronic pain: a systematic review and meta-analysis. Pain. 2011;152(3):533-42. doi: 10.1016/j.pain.2010.11.002.

26. Simpson PA, Mars T, Esteves JE. A systematic review of randomised controlled trials using Acceptance and commitment therapy as an intervention in the management of non-malignant, chronic pain in adults. Int J Osteopath Med. 2017;24:18-31. doi: 10.1016/j.ijosm.2017.03.001.

27. Yu L, McCracken LM. Model and processes of acceptance and commitment therapy (ACT) for chronic pain including a closer look at the self. Curr Pain Headache Rep. 2016;20(2):12. doi: 10.1007/s11916-016-0541-4.

28. Nejat S, Montazeri A, Holakouie Naieni K, Mohammad K, Majdzadeh SR. The World Health Organization quality of Life (WHOQOL-BREF) questionnaire: translation and validation study of the Iranian version. Journal of School of Public Health and Institute of Public Health Research. 2006;4(4):1-12. [Persian].

29. Sullivan MJL, Bishop SR, Pivik J. The pain catastrophizing scale: development and validation. Psychol Assess. 1995;7(4):52432. doi: 10.1037/1040-3590.7.4.524.

30. Mohamadi S, Dehghani M, Heidari M, Sedaghat M, Khatibi A. The evaluation of pain-related psychological similarities among patients with musculoskeletal chronic pain and their spouses. Int J Behav Sci. 2013;7(1):57-66. [Persian].

31. Picavet HS, Vlaeyen JW, Schouten JS. Pain catastrophizing and kinesiophobia: predictors of chronic low back pain. Am J Epidemiol. 2002;156(11):1028-34. doi: 10.1093/aje/kwf136.

32. Vowles KE, Sorrell JT. Life with Chronic Pain: An Acceptancebased Approach Therapist Guide and Patient Workbook. 2007. https://contextualscience.org/files/CP_Acceptance_ Manual_09.2008.pdf.

33. Johnston M, Foster M, Shennan J, Starkey NJ, Johnson A. The effectiveness of an Acceptance and Commitment Therapy selfhelp intervention for chronic pain. Clin J Pain. 2010;26(5):393402. doi: 10.1097/AJP.0b013e3181cf59ce.

34. Yazdi-Ravandi S, Taslimi Z, Haghparast A, Ghaleiha A. Quality of life in patients with chronic pain disorders: determinnation the role of intensity and duration of pain. Koomesh. 2016;17(4):836-43. [Persian].

35. Masumian S, Shairi MR, Hashemi M. The effect of mindfulnessbased stress reduction on quality of life of the patients with chronic low back pain. Journal of Anesthesiology and Pain. 2013;4(1):25-37. [Persian].

36. Hazrati M, Poor Keiani M, Abaszade A, Jaafari P. The effect of rehabilitation in quality of life in women after mastectomy. Armaghane Danesh. 2008;12(4):89-99. [Persian].

37. Patil V, Deshmukh A, Naik R, De Sousa A. A cross-sectional observational study on the levels of anxiety, depression, and somatic symptoms in patients with chronic pain undergoing physiotherapy treatment. Indian J Pain. 2016;30(2):108-10. doi: 10.4103/0970-5333.186466.

38. Trompetter HR, Bohlmeijer ET, Fox JP, Schreurs KM. Psychological flexibility and catastrophizing as associated change mechanisms during online Acceptance and Commitment Therapy for chronic pain. Behav Res Ther. 2015;74:50-9. doi: 10.1016/j.brat.2015.09.001.

39. Baxter J, Newman A, Torres C, Eyer J, Thorn B. The role of psychosocial factors in the pain experience: the relationship between depression, catastrophizing and chronic pain. J Pain. 2016;17(4):S97-8. doi: 10.1016/j.jpain.2016.01.299.

40. Rezaeian M, Ebrahimi A, Zargham M. The effect of Acceptance and Commitment Therapy on catastrophic and disabling pain in chronic pelvic pain in females. Research in Cognitive and Behavioral Sciences. 2015;4(2):17-30. [Persian]. 